\title{
POSITIVE MOOD AND INVESTMENT DECISIONS: EVIDENCE FROM COMEDY MOVIE ATTENDANCE IN THE U.S.
}

\author{
Gabriele M. Lepori ${ }^{\mathrm{a}, \mathrm{b}}$ \\ (ACCEPTED VERSION of a paper published in the journal \\ Research in International Business and Finance)
}

\begin{abstract}
Positive mood has been repeatedly shown to affect decision-making under risk. In this study I exploit the time-series variation in the domestic theatrical release of comedy movies as a natural experiment for testing the impact that happy mood (proxied by weekend comedy movie attendance) has on the demand for risky assets (proxied by the performance of the U.S. stock market). Using a sample of data from 1995 to 2010, I estimate that an increase in comedy attendance on a given weekend is followed by a decrease in equity returns on the subsequent Monday, which is consistent with the mood-maintenance hypothesis.
\end{abstract}

JEL Classification Codes: G11, G12, G14

Keywords: Positive mood, risk propensity, comedy movies, U.S. stock market, abnormal returns.

\footnotetext{
${ }^{a}$ Department of Finance, Copenhagen Business School, Solbjerg Plads 3, 2000 Frederiksberg, Denmark.

${ }^{\mathrm{b}}$ Current affiliation: Keele Management School, Keele University, Staffordshire, ST5 5BG, United Kingdom. Tel. +44 1782 733889. Email: g.lepori@keele.ac.uk. I am grateful to David Hirshleifer, Eduardo Andrade, Michael Roszkowski, Alice Isen, Alex Hetherington, Terrance Odean, Stefan Ruenzi, Laurent Vilanova, an anonymous reviewer, seminar participants at the Polytechnic Institute of New York University, Copenhagen Business School, and Maastricht University, and participants at the $1^{\text {st }}$ European Retail Investment Conference in Stuttgart, the 2011 Behavioural Finance Working Group conference at Cass Business School, the 2011 FMA European conference in Porto, the 2011 FMA conference in Denver, and the 2011 annual meeting of the Academy of Behavioral Finance and Economics for helpful comments and discussions. Any remaining errors are mine.
} 


\section{Introduction}

The role that mood plays in decision making under risk has been investigated both in the lab and in the field. ${ }^{1}$ The findings consistently show that mood can influence people's attitudes toward risk and, in turn, their choices. In the lab, subjects' moods are typically manipulated through exposure to such stimuli as short movie clips, sounds/music, short stories, and small gifts (e.g. Johnson and Tversky, 1983; Au et al., 2003; Chou et al., 2007; Isen and Patrick, 1983). Field studies focusing on mood, investment decisions, and aggregate stock market outcomes, on the other hand, generally assume that some environmental factors (e.g. sunshine, hours of daylight, sports results, religious holidays) can trigger mood changes in a large fraction of the investor population, which in turn translate into changes in risk aversion and/or optimism and affect portfolio choices (e.g. Hirshleifer and Shumway, 2003; Kamstra et al., 2003; Edmans et al., 2007; Al-Hajieh et al., 2011). The present paper attempts to bridge between these two streams of literature by exporting a popular mood-manipulation mechanism from the lab to the realm of field research. More specifically, in what follows I investigate whether exogenous fluctuations in comedy movie attendance (exposure to comedy movies being a source of mood enhancement) have an impact on the marginal American investor's decisions and, as a result, on aggregate U.S. stock returns.

A second contribution of this study is that, using real-world data, I test the predictions of two competing theories concerning the influence of positive mood on decision-making under risk. According to the so-called affect infusion model (AIM), positive mood fosters risk-prone behavior (e.g. Forgas and Bower, 1987; Chou et al., 2007), whereas the mood-maintenance hypothesis $(\mathrm{MMH})$ maintains that people in good moods tend to behave more cautiously in risky situations, especially when potential losses are real and salient, as they try to protect their current good

\footnotetext{
${ }^{1}$ Psychologists typically make a distinction among the concepts of affect, mood and emotion (e.g. Grable and Roszkowski, 2008), yet in the behavioral finance literature it is common to use such terms interchangeably. Here I will follow the latter approach.
} 
emotional state (e.g. Isen and Patrick, 1983; Isen and Geva, 1987). ${ }^{2}$ According to the AIM, one would then expect that the wave of positive mood that follows an increase in weekend comedy attendance should encourage risk taking across the population, thus boosting the demand for risky assets and increasing stock returns on the following Monday. The MMH, instead, implies that the same event should promote risk avoidance, depress the demand for risky assets, and lower equity returns.

The results of my empirical analysis are consistent with the view that positive mood affects investment decisions and lend support to the MMH. Using an instrumental variables approach to address some endogeneity issues and controlling for seasonal dynamics and other factors that may affect equity returns, I estimate that a one-standard-deviation increase in comedy attendance on a given weekend is followed by roughly a $0.11 \%$ decrease in stock returns on the subsequent Monday. This decrease is more pronounced (i.e. $0.16 \%$ ) in the more recent sub-sample, consistently with the view that the advent of the Internet and the growth of online trading has increased the fraction of unsophisticated investors in the market, the decisions of whom are more sensitive to sentiment (e.g. Ahmed et al., 2003). This mood effect is both statistically and economically significant, especially when compared to similar studies in the literature (e.g. Hirshleifer and Shumway, 2003; Cao and Wei, 2005). Its sign is consistent with the hypothesis that investors are less willing to take risks when experiencing a (movie-induced) positive mood.

In order to provide more evidence on the link of causality, I also examine the cross section of stock returns. According to Baker and Wurgler, (2006) and Kumar (2009), investor sentiment exerts a larger influence on the pricing of stocks that feature a high valuation uncertainty and that are difficult to arbitrage. Based on these insights, one would expect to observe a stronger impact of mood on the pricing of (among others) high-volatility stocks, extreme-growth stocks, distressed

\footnotetext{
${ }^{2}$ To the best of my knowledge, the stream of literature concerning the MMH has been almost entirely overlooked so far in the behavioral finance arena, while it has gained much attention from psychologists. As such, an additional contribution of this paper consists in bringing this important area of investigation to the attention of finance experts.
} 
stocks, and small-cap stocks. Indeed, when my analysis is conducted on portfolios of stocks, the marginal effect of comedy attendance is estimated to be increasing (in absolute value) in the volatility of stocks, and there is also some marginal evidence that the valuation of extreme-growth and distressed stocks is more sensitive to comedy-induced positive mood.

The rest of the paper is organized as follows. Section 2 presents the lab and field evidence on the relationship between positive affect and risk-taking behavior and discusses the MMH and AIM. Section 3 puts forward the hypothesis that will be tested. Section 4 describes the data and section 5 contains the empirical analysis. Section 6 concludes.

\section{Positive Affect and Risk Taking}

\subsection{Risk Perception and Risk Taking Propensity}

Laboratory studies have consistently documented that happy moods tend to reduce the perception of risk, at least when subjects are asked to evaluate the likelihood of some hypothetical future events or scenarios (e.g. Johnson and Tversky, 1983; Wright and Bower, 1992; Wegener et al., 1994). The evidence is more controversial, though, when one considers the studies in which, rather than having to estimate event probabilities, lab subjects are asked to make actual (or hypothetical) decisions under risk. Isen and Patrick (1983) find that happy mood fosters risk taking in a game of roulette involving low-risk bets; when high-risk bets are considered, instead, individuals in a positive mood tend to be more risk averse than controls. Similar results are obtained by Isen and Geva (1987). Arkes at al. (1988) observe that positive-affect subjects are willing to pay more for hypothetical lottery tickets but are also willing to pay more to buy insurance against hypothetical losses, especially when the potential loss is large. In a virtual foreign exchange market experiment, Au et al. (2003) find that traders in a good mood display a more risk-prone behavior than controls and bad-mood traders. On the opposite side, both Isen et al. (1988) and Nygren et al. (1996) find that, in gambling tasks where actual credit hours are at stake, positive-mood individuals 
exhibit more conservatism and a preference for avoiding losses, especially when a large loss is possible. Interestingly, this decrease in risk tolerance takes place even if positive-mood participants appear to overestimate the probabilities of winning (Nygren et al., 1996). Using happy and sad movie clips to elicit mood responses, Lin et al. (2006) and Heath (2007) observe that participants in a happy mood display more conservatism and risk aversion than the controls when presented with hypothetical everyday life dilemmas and investment decisions.

The evidence accumulated using observational data, too, is mixed. In a survey of adults who volunteered to answer a questionnaire of the type typically employed by financial advisors, Grable and Roszkowski (2008) find that people currently experiencing a happy mood display a higher level of financial risk tolerance when confronted with hypothetical investment decisions than people in a neutral mood. Hirshleifer and Shumway (2003) investigate the relationship between morning sunshine in the cities hosting a stock exchange and daily returns on the corresponding market indices. Using a sample of 26 countries, the authors document a positive correlation between the two variables, which they interpret as evidence that positive mood (allegedly triggered by sunshine) leads people to be more risk-prone and/or to evaluate future prospects more optimistically. Yet, the opposite result has been observed by Guven (2009), who employs two panel surveys to construct a direct measure of individuals' moods; he documents that unexpected sunshine increases (self-reported) individual happiness, and that increased happiness (instrumented with regional sunshine), leads people to be more risk-averse in financial decisions, to choose safer assets, and to have "less desire to invest in shares [of stock] because they find them too risky".

\subsection{Affect Infusion Model and Mood Maintenance Hypothesis}

The empirical patterns discussed in the previous section have spawned two different theories. The AIM asserts that positive mood increases risk taking (Forgas, 1995). This model finds 
support in two complementary lines of research. According to the mood-as-information model proposed by Schwarz and Clore (1983), the way people make judgments is partially affected by how they feel and, more specifically, individuals are prone to make mood-congruent assessments. In other words, people experiencing a positive mood are expected to evaluate the environment more favorably (Bower, 1981), which encourages proactive behavior. This may result from the fact that positive affect facilitates the recall of positive material in memory and thus generates judgment patterns in line with positive memories (Isen et al., 1978; Forgas and Bower, 1987). A second line of research on heuristic processing argues that people in a positive mood are likely to use a "processing strategy that relies heavily on the use of simple heuristics, and that is characterized by a lack of logical consistency and little attention to detail" (Schwarz and Bless, 1991). Individuals in a positive mood are therefore less likely to be aware of the potential negative consequences of their decisions, and a lack of careful and rational thought may intensify their risk-prone responses (Mackie and Worth, 1991; Forgas, 1998). On the opposite side, the MMH maintains that, though positive affect may improve expectations and risk estimates in some circumstances, individuals are highly protective of their good mood states (Isen and Patrick, 1983). For this reason, when making decisions under risk that may endanger their good moods, people experiencing positive affect are likely to behave cautiously and avoid taking risks (Isen and Geva, 1987; Arkes et al., 1988).

Reconciling the available findings poses a difficult task for researchers. According to Forgas (1995), the AIM is likely to dominate in contexts that require substantial information processing and an accurate evaluation of complex issues. Other authors suggest that the MMH is likely to dominate in decision frames where possible losses are real and salient (Isen and Patrick, 1983; Arkes et al., 1988), the stakes are high (Isen and Geva, 1987), and actual large losses may occur (Nygren et al., 1996). Given that investing in financial markets requires complex information 
processing and involves large potential losses, the theory alone does not seem to provide enough guidance as to which of the two effects one should expect to dominate in such a context.

\section{Hypothesis under Scrutiny}

The null hypothesis tested in this study follows directly from the classical finance paradigm, according to which individuals are rational, markets are efficient, and equity prices are unaffected by the dynamics of irrelevant factors such as comedy movie attendance and people's moods. The alternative hypothesis asserts that an exogenous increase in comedy movie attendance during the weekend generates a corresponding wave of mood enhancement across the population. In turn, the latter variable affects the marginal investor's risk taking behavior and the investment decisions that she assesses over the weekend. Given that actual trades can only be implemented when the market reopens, this chain of events will ultimately affect demand in the stock market and equilibrium prices on the following Monday.

Based on the literature discussed in the previous section, two distinct alternative hypotheses can be advanced with regard to the expected sign of this movie-induced mood effect. According to the AIM, positive mood leads to a rise in risk taking propensity, which translates into the following

Hla: an exogenous increase in the number of people that are exposed to comedies causes the net demand for risky assets to rise and increases stock returns, all else equal. On the other hand, the MMH predicts that positive mood will lead individuals to behave more cautiously, which implies that

H1b: an exogenous increase in the number of people that are exposed to comedies causes the net demand for risky assets to fall and reduces stock returns, all else equal. The formulation of these alternative hypotheses was inspired by several key pieces of evidence: (i) moviegoing is a highly popular leisure activity in the United States; according to UNESCO 
statistics, between 1995 and 2006 the U.S. constantly ranked among the top three countries in the world in terms of cinema admissions per capita. ${ }^{3}$ Domestic box office data reveal that almost twenty million people go to the movies on the typical weekend, which represents a considerable fraction of the population (see Table 1). Though teens and young adults (12-24 year-olds) tend to be overrepresented and old people (60+ year-olds) tend to be underrepresented, the age structure of moviegoers resembles that of the general population as far as the adult group is concerned (MPAA, 2007). There is also indirect evidence that moviegoers are more likely to participate in the equity market than the average American, as they are better educated, have higher incomes, are more likely to use financial services and entertainment technology, have a more active lifestyle, and are more involved in social activities (Arbitron, 2003), all of which factors are positively correlated to stock market participation (e.g. Bertaut, 1998; Guiso et al., 2003; Hong et al., 2004; van Rooij et al., 2007; Bogan, 2008).

(ii) Comedy movies, in particular, attract large audiences (see Figure 1). Comedy blockbusters generate sales that tend to be concentrated in the first few weekends after release and quickly fall over time. For this reason, both the number of screens dedicated to comedies (see Figure 2) and comedy admissions exhibit a conspicuous variability over time, which makes it possible to identify the effect of interest.

(iii) There is both lab and field evidence that the movie experience can produce intense and unambiguous mood states in moviegoers, which in turn can translate into changes in risk taking (see section 2.1). Forgas and Moylan (1988) find no evidence of self-selection when approaching individuals before they entered the movie theater, but do find evidence that happy films positively affect beliefs after exposure. In a meta-analysis, Westermann et al. (1996) observe that, among the

\footnotetext{
${ }^{3}$ http://stats.uis.unesco.org/unesco/ReportFolders/ReportFolders.aspx.
} 
mood induction procedures adopted in the literature, videotapes and films produce the strongest effect when it comes to inducing positive mood in the lab.

\section{Intended for color reproduction on the}

Web, black-and-white in print.



Figure 1. Plot of weekend (Friday through Sunday) viewers of comedy movies in the domestic market. Movies are sorted by genre according to the classification provided by www.the-numbers.com. The six weekends with the largest number of spectators are labeled with the top grossing movie of the week. The audience data are obtained by deflating box-office revenues (from www.the-numbers.com) by the average ticket price.

Intended for color reproduction on the

Web, black-and-white in print.

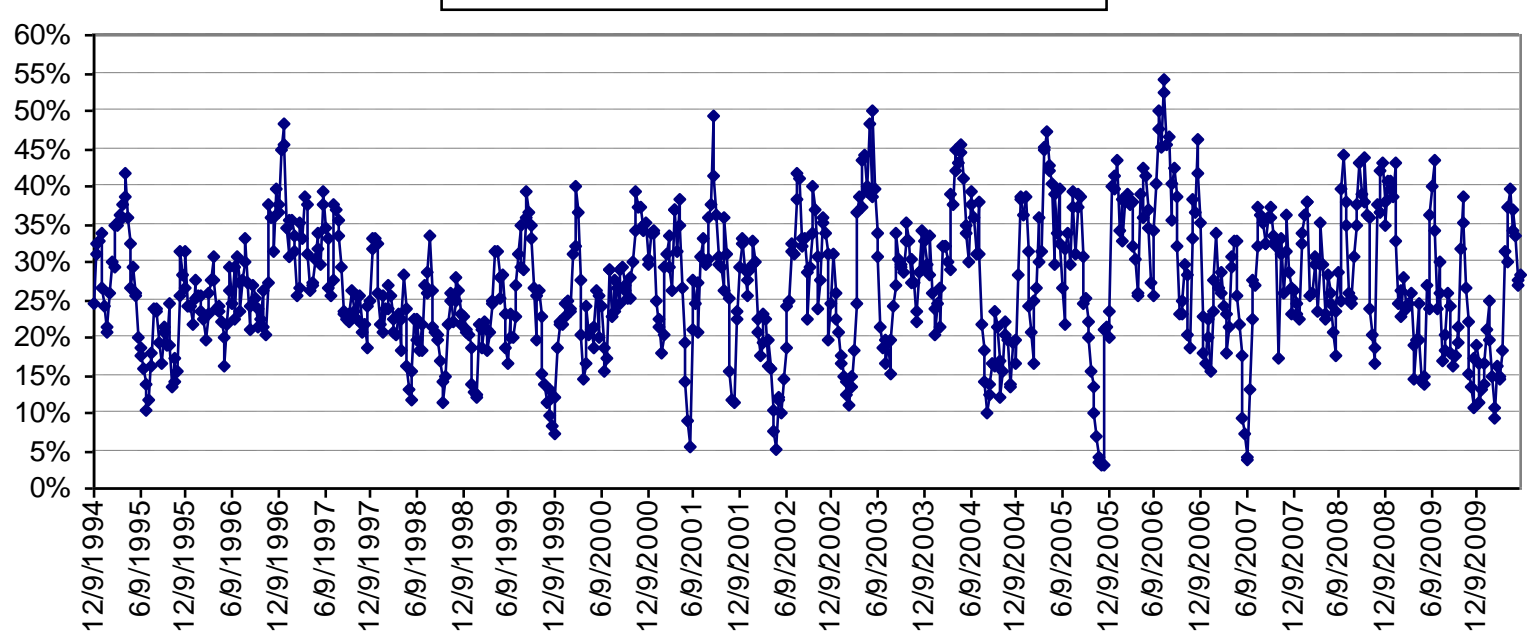

Figure 2. Plot of the percentage of domestic theaters playing a comedy movie by weekend (Friday through Sunday). Movies are sorted by genre according to the classification provided by www.the-numbers.com. Theater count data are obtained from www.the-numbers.com, which defines a theater as "any place a movie is showing from the smallest cinema on the art house circuit to the largest megaplex". 
(iv) There is evidence that individual investors are more likely to ponder trading decisions on weekends and conduct actual trades on Mondays, whereas professional investors have a propensity to trade less on Mondays (Venezia and Shapira, 2007; Chan et al., 2004; Abraham and Ikenberry, 1994). This implies that the risky investment decisions that retail investors contemplate during the weekend may be affected by their weekend mood, which in turn may be influenced by their exposure to comedy movies.

(v) So-called "behavioral consistency" suggests that transient mood may have a lasting impact on decision making. According to Andrade and Ariely (2009) people tend to "behave consistently with past actions and cognitions", so that if an initial decision/action is contaminated by an incidental emotional state, subsequent decisions are likely to follow suit, in turn prolonging the effect of said state.

(vi) Previous research has documented that international markets are not fully integrated and there exists a deep home-equity bias (e.g. Levi, 1997; Lewis, 1999), so that domestic investors and institutions are likely to exert a major influence on the dynamics of the U.S. stock market. All of this suggests that a mood enhancement experienced during the weekend by a large segment of U.S. investors (caused by their attending a comedy movie) may well have a domestic market impact through their ensuing trades on the following Monday.

\section{Data}

In the empirical analysis I employ U.S. daily stock returns taken from the Center for Research in Security Prices (CRSP). More specifically, I select the equal-weighted returns and the value-weighted returns (both including distributions) calculated for the NYSE/AMEX/NASDAQ market combination over the period December 1, 1994 through December 31, 2009. For robustness purposes, I also examine the returns on the S\&P500, Dow Jones Industrial, NYSE Composite, and 
NASDAQ Composite indices, all obtained from Datastream. ${ }^{4}$ The sample period in this case extends from December 1, 1994 through May 31, 2010. To examine the cross section of stock returns, I use Fama and French (1992)'s ten value-weighted portfolios sorted by industry, size, and book-to-market ratio. Additionally, I employ CRSP value-weighted returns calculated on standard deviation-based deciles for the NYSE/AMEX market combination.

Domestic movie box office data and movie details are taken from a database hosted on the website www.the-numbers.com. In my analysis I focus on weekend (Friday through Sunday) boxoffice revenues for two reasons. First, movie attendance is much higher on weekends than during week days, which means a larger fraction of the population may be affected by movie-induced mood shifts at such times. Second, detailed weekend box-office data are available for a reasonably long period of time (from December 9, 1994 through May 28, 2010), whereas daily data are only available for the top 10 grossing movies starting from 1997. The sample that I employ comprises 808 weekends and 7,246 unique movie titles. On the typical weekend, roughly one hundred different movies are playing in theaters across the country, and the average movie stays in the theaters for about eleven weeks after its release. Movies are classified by www.the-numbers.com into twelve mutually exclusive genres: comedy, adventure, drama, action, thriller/suspense, romantic comedy, horror, documentary, musical, black comedy, western, and concert/performance. Comedy movies account for approximately $24.2 \%$ of total domestic gross revenue (and $18 \%$ of the movie releases) between January 1995 and May 2010. ${ }^{5}$ To estimate the number of viewers of comedy movies in each weekend, first I obtain annual average ticket prices from the National Association of Theater Owners (NATO), and then I follow Einav (2007) and I compute weekly

\footnotetext{
${ }^{4}$ The Datastream codes for such indices are S\&PCOMP, DJINDUS, NYSEALL, and NASCOMP, respectively.

${ }^{5}$ For a very small number of movies in the database the genre label is missing. They account for roughly $0.12 \%$ of domestic gross revenue in the sample under observation. These are typically small movie productions that tend to attract a negligible number of moviegoers. For simplicity, in all the computations reported below I assume these movies do not belong to the comedy genre, but I do include their audiences in the count of total weekend moviegoers. As an alternative, in unreported calculations, I assumed that all these movies belonged to the comedy genre and I obtained virtually identical results.
} 
ticket prices by linearly interpolating annual prices. The number of viewers in each weekend is then calculated by dividing the relevant box-office revenues by the estimated weekly ticket price.

From www.the-numbers.com I also extract the number of theaters in which any given comedy movie is playing at any given point in time. ${ }^{6}$ As a result, over the sample period, I am able to observe both the number of people that went to see a comedy movie on weekend $t$ and the percentage of theaters showing a comedy movie on weekend $t$ (see Figure 2 and Table 1). I then use data from disparate sources to construct a set of environmental controls, which are described in detail in the Appendix. Some summary statistics are displayed in Table 2.

Table 1

Movie Audiences and Theaters Count - Descriptive Statistics

Panel a of this table displays some summary statistics concerning domestic weekend movie admissions by movie genre. The sample covers the period from December 9, 1994 through May 31, 2010. Panel b shows some summary statistics about the number of theater screens allocated to different movie genres over the same period of time.

\begin{tabular}{|c|c|c|c|c|}
\hline & Average & Standard Deviation & Min & Max \\
\hline \multicolumn{5}{|c|}{ (a) Movie Audience for Weekends (Friday - Sunday) } \\
\hline Comedy & $\begin{array}{l}4,674,859 \\
\text { (808 obs.) }\end{array}$ & $2,826,026$ & 191,053 & $17,054,450$ \\
\hline Romantic Comedy & $\begin{array}{l}1,161,658 \\
\text { (808 obs.) }\end{array}$ & $1,430,738$ & 0 & $9,399,947$ \\
\hline Black Comedy & $\begin{array}{c}85,255 \\
\text { (808 obs.) }\end{array}$ & 253,574 & 0 & $2,650,446$ \\
\hline $\begin{array}{l}\text { Total admissions } \\
\text { (All Genres) }\end{array}$ & $\begin{array}{c}19,036,100 \\
(808 \text { obs.) }\end{array}$ & $4,846,434$ & $9,382,466$ & $36,964,034$ \\
\hline \multicolumn{5}{|c|}{ (b) \# of Movie Theaters for Weekends (Friday - Sunday) } \\
\hline Comedy & $\begin{array}{c}10,203 \\
\text { (808 obs.) }\end{array}$ & 3,669 & 1,072 & 21,176 \\
\hline Romantic Comedy & $\begin{array}{c}2,519 \\
(808 \text { obs.) }\end{array}$ & 2,103 & 0 & 10,791 \\
\hline Black Comedy & $\begin{array}{c}232 \\
\text { (808 obs.) }\end{array}$ & 545 & 0 & 3,331 \\
\hline $\begin{array}{l}\text { Total \# of Theaters } \\
\text { (All Genres) }\end{array}$ & $\begin{array}{c}37,681 \\
\text { (808 obs.) }\end{array}$ & 4,101 & 25,431 & 48,946 \\
\hline
\end{tabular}

${ }^{6}$ According to www.the-numbers.com's definition, a theater is "any place a movie is showing from the smallest cinema on the art house circuit to the largest megaplex". 


\section{Table 2}

\section{Environmental Mood Triggers - Descriptive Statistics}

This table reports some descriptive statistics about the set of environmental factors employed as mood controls in the empirical analysis. Panel a contains some information about daily average temperature, rain, and wind speed in New York City (LaGuardia airport) over the period December 1, 1994 through May 31, 2010. Panel b contains some information about a set of daily proxies for the fraction of the U.S. population exposed to a selection of weather events (e.g. snow, thunderstorms, extreme hot or cold temperatures) over the same period of time.

\begin{tabular}{lcccc}
\hline \hline & Average & Standard Deviation & Min & Max \\
\hline $\begin{array}{l}\text { (a) New York weather variables } \\
\text { Average Temperature in New York }\left(\mathrm{F}^{\circ}\right)\end{array}$ & $55.49(5660$ obs. $)$ & 16.87 & 8.5 & 93.6 \\
Rain in New York (dummy: yes $=1)$ & $0.35(5660$ obs. $)$ & 0.48 & 0 & 1 \\
Average Wind Speed in New York (knots) & $9.56(5660$ obs.) & 3.38 & 1.8 & 25.4 \\
C9 Geomagnetic Index (0-to-9 scale) & 2.20 (5661 obs.) & 2.08 & 0 & 9
\end{tabular}

(b) U.S. weather variables

Snow (fraction of U.S. population exposed to)

Rain (fraction of U.S. population exposed to)

Fog (fraction of U.S. population exposed to)

Hail (fraction of U.S. population exposed to)

Thunderstorm (fraction of U.S. population exposed to)

Tornado (fraction of U.S. population exposed to)

High Max Temperature $\left(\mathrm{F}^{\circ}>100\right)$

(fraction of U.S. population exposed to)

High Max Temperature $\left(90<\mathrm{F}^{\circ} \leq 100\right)$

(fraction of U.S. population exposed to)

High Max Temperature $\left(80<\mathrm{F}^{\circ} \leq 90\right)$

(fraction of U.S. population exposed to)

Low Min Temperature $\left(\mathrm{F}^{\circ} \leq 10\right)$

(fraction of U.S. population exposed to)

Low Min Temperature $\left(10<\mathrm{F}^{\circ} \leq 20\right)$

(fraction of U.S. population exposed to)

Low Min Temperature $\left(20<\mathrm{F}^{\circ} \leq 32\right)$

(fraction of U.S. population exposed to)

High Max Wind Speed (knots > 21)

(fraction of U.S. population exposed to)

High Max Wind Speed $(17<$ knots $\leq 21)$

(fraction of U.S. population exposed to)

\begin{tabular}{|c|c|c|c|}
\hline 0.07 (5655 obs.) & 0.11 & 0 & 0.58 \\
\hline 0.31 (5655 obs.) & 0.16 & 0 & 0.91 \\
\hline 0.28 (5655 obs.) & 0.19 & 0 & 0.94 \\
\hline 0.001 (5655 obs.) & 0.01 & 0 & 0.13 \\
\hline 0.09 (5655 obs.) & 0.1 & 0 & 0.56 \\
\hline 0.0003 (5655 obs.) & 0.005 & 0 & 0.16 \\
\hline 0.02 (5655 obs.) & 0.04 & 0 & 0.31 \\
\hline 0.11 (5655 obs.) & 0.16 & 0 & 0.89 \\
\hline 0.23 (5655 obs.) & 0.22 & 0 & 0.91 \\
\hline 0.02 (5655 obs.) & 0.06 & 0 & 0.56 \\
\hline 0.05 (5655 obs.) & 0.09 & 0 & 0.61 \\
\hline 0.15 (5655 obs.) & 0.18 & 0 & 0.79 \\
\hline 0.06 (5655 obs.) & 0.08 & 0 & 0.65 \\
\hline 0.13 (5655 obs.) & 0.09 & 0 & 0.56 \\
\hline
\end{tabular}




\section{Empirical Analysis}

\subsection{Classical Tests of Hypotheses}

I begin my analysis by examining whether mean post-weekend stock returns systematically differ depending on the number of people exposed to comedy films during the weekend. To accomplish this, I sort all Monday returns into three categories depending on whether the number of comedy movie admissions during the previous weekend is at least one standard deviation above the mean (i.e. "high-comedy" weekends), within one standard deviation of the mean, or at least one standard deviation below the mean (i.e. "low-comedy" weekends). I then compute the mean Monday return for each category and compare them using a two-sample t-test. The results, reported in panel a of Table 3, reveal that mean Monday returns monotonically decrease as the population's level of exposure to comedy films increases. More specifically, a t-test shows that the difference between the mean Monday return following "high-comedy" weekends and the mean Monday return following "low-comedy" weekends is statistically significant at least at the 5\% level. Said difference is economically significant for both the equal-weighted (-0.446\%) and value-weighted ($0.394 \%$ ) returns. Panel $\mathrm{b}$ of Table 3 also reveals that the proportion of positive-return Mondays monotonically decreases as the population's level of exposure to comedy films increases. More in detail, a two-sample proportion test reveals that the fraction of positive-return Mondays following "high-comedy" weekends is statistically significantly lower than the fraction of positive-return Mondays following "low-comedy" weekends. The mean-comparison and the proportion tests therefore lend some initial support to the hypothesis that movie-induced positive mood reduces the demand for risky assets and lowers stock returns. Obviously, there might be some other confounding factors at play. To address such an issue I now turn to a regression framework. 
Table 3

Mean Monday Returns and Proportion of Positive-Return Mondays by Comedy Movie Attendance

This table displays some summary statistics of the daily stock returns on Mondays. The Monday returns are sorted into three groups by comedy movie attendance levels on the previous weekend: "high-comedy" weekends refer to the weekends in which the number of people watching a comedy is at least one standard deviation above the mean; "lowcomedy" weekends are weekends in which the number of people watching a comedy is at least one standard deviation below the mean; "regular Mondays" refer to the Mondays following weekends in which the number of people watching a comedy is within one standard deviation of the mean. Panel a shows the mean Monday return for each of the three groups mentioned above. The last column reports the results of a t-test comparing the mean Monday returns after highcomedy and low-comedy weekends. Panel $b$ shows the proportion of positive-return Mondays for each of the three groups mentioned above. The last column reports the results of a proportion test comparing the proportions of positivereturn Mondays after high-comedy and low-comedy weekends. One, two, and three asterisks denote statistical significance at the ten, five, and one percent, respectively. Returns are expressed in percentage points.

(a) Mean daily stock returns by comedy movie attendance levels

\begin{tabular}{|c|c|c|c|c|}
\hline \multirow[b]{2}{*}{ Stock market index } & \multicolumn{3}{|c|}{ Mean daily return $(\%)$} & \multirow[b]{2}{*}{$\mathrm{H}-\mathrm{L}$} \\
\hline & $\begin{array}{l}\text { Mondays after high- } \\
\text { comedy weekends } \\
(\mathrm{H})\end{array}$ & $\begin{array}{l}\text { Regular } \\
\text { Mondays }\end{array}$ & $\begin{array}{l}\text { Mondays after low- } \\
\text { comedy weekends } \\
\text { (L) }\end{array}$ & \\
\hline Equal-Weighted Returns & -0.270 & -0.054 & 0.177 & $-0.446 * * *$ \\
\hline Value-Weighted Returns & -0.228 & 0.009 & 0.166 & $-0.394 * *$ \\
\hline \multicolumn{5}{|c|}{ (b) Proportion of positive-return days by comedy movie attendance levels } \\
\hline & \multicolumn{3}{|c|}{ Proportion } & \\
\hline Stock market index & $\begin{array}{c}\text { Mondays after high- } \\
\text { comedy weekends } \\
\left(\mathrm{P}_{\mathrm{H}}\right)\end{array}$ & $\begin{array}{l}\text { Regular } \\
\text { Mondays }\end{array}$ & $\begin{array}{c}\text { Mondays after low- } \\
\text { comedy weekends } \\
\left(\mathrm{P}_{\mathrm{L}}\right)\end{array}$ & $P_{H}-P_{L}$ \\
\hline Equal-Weighted Returns & 0.412 & 0.546 & 0.615 & $-0.202 * * *$ \\
\hline Value-Weighted Returns & 0.454 & 0.540 & 0.594 & $-0.140 *$ \\
\hline
\end{tabular}

\subsection{Baseline Regression Model}

I start my regression analysis with a simple OLS model that regresses stock returns on comedy movie attendance and a few controls. More in detail, I estimate the following equation and perform statistical inference adopting Newey-West (1987) adjusted standard errors (max 5 lags):

$$
\begin{aligned}
R_{t}= & \alpha+\beta_{C O M} M_{t} \times \ln \left(\text { COM }_{t-1}\right)+\beta_{S P E C T} M_{t} \times \ln \left(\text { SPECT }_{t-1}\right)+\gamma_{M} M_{t}+ \\
& +\gamma_{T A X} T A X_{t}+\sum_{j=1}^{5} \gamma_{1 k} R_{t-k}+\sum_{k=1}^{11} \gamma_{2 k} M T H_{k t}+\varepsilon_{t}
\end{aligned}
$$


where $R_{t}$ measures the CRSP equal-weighted (or value-weighted) return on day $t, M$ is a dummy that takes value 1 on Mondays and 0 otherwise (e.g. Gibbons and Hess, 1981; Ko et al., 1997), $\ln$ is the natural logarithm function, $C O M_{t-1}$ measures the number of people watching comedy movies on the weekend (Friday through Sunday) that precedes Monday $t$, and TAX is a dummy that takes value 1 over the first seven days of January and 0 otherwise (e.g. Keim, 1983; Dyl and Maberly, 1992). ${ }^{7}$

Five lagged returns are included in each regression model to control for the serial autocorrelation of equity returns (e.g. Tetlock, 2007). $M T H_{k}$ is a dummy meant to control for monthly patterns in stock returns (e.g. Baur, 2013), and it takes value 1 in the $k^{\text {th }}$ calendar month and 0 otherwise. SPECT $T_{t-1}$ measures the total number of spectators in movie theaters (i.e. regardless of movie genre) on the weekend that precedes Monday $t$. This last variable is included to control for several effects: (a) movie ticket sales have a direct economic effect on the revenues of film studios, many of which are owned by companies whose shares are traded in a U.S. stock exchange $;^{8}$ (b) since seasonal dynamics affect stock returns (e.g. Kamstra et al., 2003), movie release dates, and consumer demand for movies (Einav, 2007), the covariate SPECT should control for seasonalities that are common to all movie genres; (c) the experience of going to the movies, per se (i.e. regardless of movie genre), may have some influence on people's emotional states, and it displaces the consumer's next-best alternative activity, which might also have affected her emotional state. ${ }^{9}$

\footnotetext{
${ }^{7}$ More precisely, the variable $C O M$ measures the audience size for comedy movies +1 person. This measurement technique is applied throughout the paper to all variables that measure some type of movie attendance and enter the regression model in a logarithmic form, so that they never take value 0 .

${ }^{8}$ Between 1995 and 2009, approximately 93\% of the gross box-office revenues were generated by film studios that are currently owned by one of the following companies: Walt Disney Company, Time Warner, Sony Corporation, Viacom, News Corporation, General Electric Company, and Lions Gate Entertainment Corporation. These companies are presently listed on either the NYSE or NASDAQ.

${ }^{9}$ Leisure activities, among which moviegoing, can provide relaxation, recovery from fatigue, and reduce anxiety (Hull and Michael, 1995). Furthermore, the audio-visual stimulation generated by the cinematic experience may produce an increased physiological arousal in the viewer (Reeves et al., 1985; Lang, 1990), which has been linked to higher risk seeking (Mano, 1994).
} 


\section{Table 4}

\section{Exposure to Comedy Movies and Stock Returns - Baseline Model}

This table displays a subset of the coefficient estimates for regression [1]. The coefficients on the five lagged returns and monthly dummies are not reported due to space limitations. Newey-West standard errors are shown in parenthesis below the corresponding coefficients. One, two, and three asterisks denote statistical significance at the ten, five, and one percent level, respectively. Returns are measured in percentage points.

\begin{tabular}{|c|c|c|c|}
\hline & Dep. Var.: & $\begin{array}{c}\text { Equal-Weighted } \\
\text { Returns }\end{array}$ & $\begin{array}{c}\text { Value-Weighted } \\
\text { Returns }\end{array}$ \\
\hline & & (1) & (2) \\
\hline$\alpha$ & & $\begin{array}{c}0.163 * * * \\
(0.001)\end{array}$ & $\begin{array}{c}0.126 * * \\
(0.024)\end{array}$ \\
\hline$\beta_{\mathrm{COM}}$ & & $\begin{array}{c}-0.1211 * * \\
(0.0587)\end{array}$ & $\begin{array}{l}-0.1133 * \\
(0.0682)\end{array}$ \\
\hline$\beta_{\text {SPECT }}$ & & $\begin{array}{c}0.028 \\
(0.184)\end{array}$ & $\begin{array}{l}-0.063 \\
(0.216)\end{array}$ \\
\hline$\gamma_{M}$ & & $\begin{array}{c}1.175 \\
(3.175)\end{array}$ & $\begin{array}{c}2.705 \\
(3.713)\end{array}$ \\
\hline$\gamma_{\text {TAX }}$ & & $\begin{array}{c}0.226 \\
(0.162)\end{array}$ & $\begin{array}{c}0.101 \\
(0.182)\end{array}$ \\
\hline Observations & & 3794 & 3794 \\
\hline F statistic & & 3.26 & 0.90 \\
\hline
\end{tabular}

The relevant results for the equal-weighted and value-weighted returns are reported in column (1) and (2), respectively, of Table 4. The sign and magnitude of the coefficient on COM are consistent across the two return definitions. Other things equal, a one-standard-deviation increase in comedy admissions on a given weekend is estimated to be followed by a $0.06 \%$ reduction in equity returns on the subsequent Monday. ${ }^{10}$ When CRSP equal-weighted (value-weighted) returns are considered, the marginal effect is statistically significant at the 5\% (10\%) level. The sign of this effect is consistent with a fall in investors' net demand for risky assets, which in turn is consistent with domestic investors behaving more cautiously when experiencing a movie-induced positive

\footnotetext{
${ }^{10}$ Taking the average number of viewers of comedy films as a baseline, and holding all other regressors constant (with $M=1$ ), a one-standard-deviation increase in comedy film audience size is estimated to have the following impact on next-day returns:$$
\left.E(R)\right|_{\mathrm{COM}_{2}}-\left.E(R)\right|_{\mathrm{COM}_{1}}=\beta_{\mathrm{COM}} \times \ln \left(\frac{\mathrm{COM}_{2}}{\mathrm{COM}_{1}}\right)=\beta_{\mathrm{COM}} \times \ln \left(\frac{\overline{\mathrm{COM}}+\sigma_{\mathrm{COM}}}{\overline{\mathrm{COM}}}\right)=-0.06
$$ 
mood. On the other hand, there seems to be no evidence that going to the movies per se has any impact on aggregate equity returns, as the coefficient on SPECT is estimated to be close to zero and is statistically insignificant across the two return definitions. ${ }^{11}$

\subsection{Endogeneity Issues}

\subsubsection{Controlling for Environmental Mood Triggers}

Arguably, the correlation between comedy movie attendance and stock returns discussed in the previous sections may be the result of some unobserved economic factors that jointly affect the size of comedy audiences on weekends and equity returns on the following Mondays. Also, people's pre-existing moods over the weekend may have an impact on their choice between going to the movies and alternative forms of leisure, their choice between alternative movie genres, and the investment decisions that they will implement on the subsequent Monday. ${ }^{12}$ To address the former concern, in the next section I will employ an instrumental variables approach. To deal with the latter concern, here I attempt to control for some environmental factors that may generate collective mood shifts across the population over the weekend. More specifically, I augment model [1] with a set of environmental covariates (see the Appendix and Table 2), as follows:

$$
\begin{aligned}
R_{t}= & \alpha+\beta_{C O M} M_{t} \times \ln \left(\text { COM }_{t-1}\right)+\beta_{\text {SPECT }} M_{t} \times \ln \left(\operatorname{SPECT}_{t-1}\right)+\gamma_{M} M_{t}+ \\
& +\gamma_{T A X} T A X_{t}+\sum_{j=1}^{5} \gamma_{1 k} R_{t-k}+\sum_{k=1}^{11} \gamma_{2 k} M T H_{k t}+\mathrm{X}_{t}^{\prime} \delta+\varepsilon_{t}
\end{aligned}
$$

where $X_{t}$ is a vector of daily variables proxying for: (a) the seasonal affective disorder in the U.S.,

(b) disturbances of the Earth's magnetosphere, (c) the lunar cycle, and (d) the percentage of

\footnotetext{
${ }^{11}$ Imposing some restrictions such as $\beta_{C O M}=0, \beta_{S P E C T}=0$, or $\gamma_{M}=0$ does not alter the estimates of the coefficients of interest in a significant way. The same is true when estimating model [1] using an IV approach, which is done in section 5.3.2. I thank an anonymous reviewer for suggesting this kind of robustness test.

${ }^{12}$ Some authors claim that individuals tend to choose mood-congruent media content (Oliver, 1993; 2003), while others argue that mood-incongruent media content is likely to be selected as people tend to engage in mood-management processes (Zillmann, 1988).
} 
Americans that on day $t-1$ and $t-2$ have been exposed to extremely high temperatures, extremely low temperatures, strong winds, snow, rain, fog, hail, thunderstorms, and tornados. $X_{t}$ also contains three variables that measure the average temperature, rainfall (yes $=1$, no $=0$ ), and wind speed in New York City. A relevant subset of model [2]'s estimated coefficients is reported in Table 5, revealing no substantial changes in the marginal effect of COM compared to Table 4. The same applies to the coefficient on SPECT, which is again estimated to be close to zero and statistically insignificant. Among the environmental triggers considered here, only the coefficients on the newmoon dummy and the snow (at lag 1) and thunderstorm (at lag 2) proxies appear to be marginally statistically significant. For this reason, this set of controls will be excluded throughout the rest of the analysis. It is worth emphasizing, though, that all the results presented below are virtually unaffected by their inclusion.

\subsubsection{Instrumental Variables Estimation}

The second approach consists in instrumenting for weekend comedy movie audience using information on the percentage of theaters in which comedies are playing. According to Moretti (2008), "the number of screens dedicated to a movie in its opening weekend reflects the sales expectations held by the market", as theater owners have an incentive to maximize profits by correctly predicting consumer demand. This suggests that the number of theater screens allocated to a given movie is likely to be highly correlated to the number of spectators of the same movie.

Furthermore, the former seems to represent a reasonable source of exogenous variation in the latter; 
Table 5

Exposure to Comedy Movies and Stock Returns - Controlling for Environmental Mood Triggers

This table displays a subset of the coefficient estimates for regression [2]. The coefficients on the five lagged returns and monthly dummies are not reported due to space limitations. Newey-West standard errors are shown in parenthesis next to the corresponding coefficients. One, two, and three asterisks denote statistical significance at the ten, five, and one percent level, respectively. Returns are measured in percentage points.

\begin{tabular}{|c|c|c|c|c|}
\hline \multirow[t]{3}{*}{ Dep. Var.: } & \multirow{2}{*}{\multicolumn{2}{|c|}{$\begin{array}{c}\text { Equal-Weighted Returns } \\
\text { (1) }\end{array}$}} & \multirow{2}{*}{\multicolumn{2}{|c|}{$\begin{array}{c}\text { Value-Weighted Returns } \\
\text { (2) }\end{array}$}} \\
\hline & & & & \\
\hline & -0.010 & $(0.979)$ & 0.220 & $(0.620)$ \\
\hline$\beta_{\mathrm{COM}}$ & $-0.1174 * *$ & $(0.043)$ & $-0.1119 *$ & $(0.098)$ \\
\hline$\beta_{\text {SPECT }}$ & -0.008 & $(0.964)$ & -0.078 & $(0.723)$ \\
\hline$\gamma_{\mathrm{M}}$ & 1.728 & $(0.591)$ & 2.934 & $(0.435)$ \\
\hline$\gamma_{\mathrm{TAX}}$ & 0.185 & $(0.265)$ & 0.081 & $(0.674)$ \\
\hline Average temperature in New York & -0.002 & $(0.604)$ & -0.002 & $(0.558)$ \\
\hline Average wind speed in New York & 0.002 & $(0.727)$ & 0.003 & $(0.690)$ \\
\hline Rain in New York & -0.056 & $(0.143)$ & -0.062 & $(0.186)$ \\
\hline Fall & $-0.247 * * *$ & $(0.002)$ & $-0.214 * *$ & $(0.022)$ \\
\hline SAD & 0.152 & $(0.139)$ & 0.092 & $(0.454)$ \\
\hline Geomagnetic storm & -0.030 & $(0.624)$ & -0.075 & $(0.334)$ \\
\hline New-moon & $0.090 * *$ & $(0.032)$ & $0.090 *$ & $(0.081)$ \\
\hline Full-moon & 0.062 & $(0.156)$ & 0.057 & $(0.259)$ \\
\hline High max temperature $\left(\mathrm{F}^{\circ}>100\right)_{\mathrm{t}-1}$ & 0.973 & $(0.216)$ & 0.376 & $(0.697)$ \\
\hline High max temperature $\left(\mathrm{F}^{\circ}>100\right)_{\mathrm{t}-2}$ & -1.147 & $(0.114)$ & -0.847 & $(0.347)$ \\
\hline High max temperature $\left(90<\mathrm{F}^{\circ} \leq 100\right)_{\mathrm{t}-1}$ & -0.042 & $(0.903)$ & -0.276 & $(0.535)$ \\
\hline High max temperature $\left(90<\mathrm{F}^{\circ} \leq 100\right)_{\mathrm{t}-2}$ & -0.428 & $(0.188)$ & -0.254 & $(0.548)$ \\
\hline High max temperature $\left(80<\mathrm{F}^{\circ} \leq 90\right)_{\mathrm{t}-1}$ & 0.171 & $(0.501)$ & 0.087 & $(0.772)$ \\
\hline High max temperature $\left(80<\mathrm{F}^{\circ} \leq 90\right)_{\mathrm{t}-2}$ & -0.220 & $(0.351)$ & -0.245 & $(0.385)$ \\
\hline Low min temperature $\left(\mathrm{F}^{\circ} \leq 10\right)_{\mathrm{t}-1}$ & -0.164 & $(0.769)$ & -0.102 & $(0.880)$ \\
\hline Low min temperature $\left(\mathrm{F}^{\circ} \leq 10\right)_{\mathrm{t}-2}$ & 0.376 & $(0.472)$ & 0.426 & $(0.512)$ \\
\hline Low min temperature $\left(10<\mathrm{F}^{\circ} \leq 20\right)_{\mathrm{t}-1}$ & -0.377 & $(0.367)$ & -0.369 & $(0.450)$ \\
\hline Low min temperature $\left(10<\mathrm{F}^{\circ} \leq 20\right)_{\mathrm{t}-2}$ & $0.703 *$ & $(0.094)$ & 0.304 & $(0.539)$ \\
\hline Low min temperature $\left(20<\mathrm{F}^{\circ} \leq 32\right)_{\mathrm{t}-1}$ & -0.374 & $(0.218)$ & -0.435 & $(0.229)$ \\
\hline Low min temperature $\left(20<\mathrm{F}^{\circ} \leq 32\right)_{\mathrm{t}-2}$ & 0.244 & $(0.412)$ & 0.323 & $(0.360)$ \\
\hline High max wind speed $(\text { knots }>21)_{\mathrm{t}-1}$ & 0.216 & $(0.398)$ & 0.138 & $(0.653)$ \\
\hline High max wind speed $(\text { knots }>21)_{\mathrm{t}-2}$ & -0.057 & $(0.832)$ & -0.205 & $(0.520)$ \\
\hline High max wind speed $(17<\text { knots } \leq 21)_{\mathrm{t}-1}$ & 0.216 & $(0.310)$ & 0.377 & $(0.145)$ \\
\hline High max wind speed $(17<\text { knots } \leq 21)_{t-2}$ & 0.163 & $(0.466)$ & 0.161 & $(0.540)$ \\
\hline $\operatorname{Fog}_{t-1}$ & -0.072 & $(0.645)$ & -0.117 & $(0.558)$ \\
\hline Fog $_{\mathrm{t}-2}$ & 0.068 & $(0.676)$ & -0.029 & $(0.884)$ \\
\hline
\end{tabular}


Table 5

(continued)

Dep. Var.: Equal-Weighted Returns

Value-Weighted Returns

\begin{tabular}{|c|c|c|c|c|}
\hline \multirow[b]{2}{*}{ Snow $_{t-1}$} & \multicolumn{2}{|c|}{ (1) } & \multicolumn{2}{|c|}{ (2) } \\
\hline & $-0.749 * *$ & $(0.034)$ & $-0.829 * *$ & $(0.048)$ \\
\hline Snow $_{t-2}$ & 0.098 & $(0.802)$ & 0.093 & $(0.839)$ \\
\hline Rain $_{t-1}$ & -0.057 & $(0.726)$ & -0.048 & $(0.808)$ \\
\hline Rain $_{t-2}$ & -0.027 & $(0.861)$ & -0.053 & $(0.780)$ \\
\hline Hail $_{t-1}$ & -1.209 & $(0.555)$ & -1.712 & $(0.521)$ \\
\hline Hail $_{t-2}$ & -1.285 & $(0.471)$ & -0.218 & $(0.918)$ \\
\hline Thunderstorm $_{\mathrm{t}-1}$ & -0.061 & $(0.848)$ & 0.140 & $(0.712)$ \\
\hline Thunderstorm $_{\mathrm{t}-2}$ & $0.480^{*}$ & $(0.089)$ & 0.420 & $(0.233)$ \\
\hline Tornado $_{\mathrm{t}-1}$ & -1.425 & $(0.512)$ & 0.564 & $(0.845)$ \\
\hline Tornado $_{\mathrm{t}-2}$ & -1.818 & $(0.385)$ & -2.228 & $(0.379)$ \\
\hline Observations & 3783 & & 3783 & \\
\hline F statistic & 2.08 & & 0.87 & \\
\hline
\end{tabular}

for instance, if few theaters are covering a given movie genre at a given point in time, then consumers are essentially "forced" to either choose an alternative genre or an alternative form of leisure. ${ }^{13}$ Additionally, since screen allocations are finalized one to two weeks in advance by theater owners (Moretti, 2008; Dahl and DellaVigna, 2009), the percentage of theaters in which comedies are playing on weekend $t$ is unrelated to (a) unexpected economic news hitting the market during weekend $t$, (b) pre-existing consumer mood conditions, and (c) other events that may take place during the weekend and will be incorporated into stock prices on the following Monday. All these attributes contribute to render the chosen instrument a valid instrument.

Estimating equation [1] by 2 SLS using equal-weighted (value-weighted) returns as the dependent variable generates the results reported in the first (second) column of Table 6, which also displays $H A C$ robust standard errors computed following Baum et al. (2007). ${ }^{14}$ Based on the C statistic test (Baum et al., 2010), the null hypothesis that comedy movie attendance can be treated as

\footnotetext{
${ }^{13}$ As Figure 2 shows, at times even less than $5 \%$ of the theater screens are dedicated to comedy movies, whereas at other times this value can be as high as $50 \%$.

${ }^{14}$ The IVREG2 Stata routine that I run uses the Bartlett kernel function and an automatic bandwidth selection criterion following Newey and West (1994).
} 
exogenous is rejected at the $10 \%$ confidence level. To document the strength of the instrument used here, I report the Wald rk F statistic based on Kleibergen and Paap (2006). According to Baum et al. (2007), when testing for weak identification in the presence of non i.i.d. errors, it may be a good idea to "refer to the older «rule of thumb» of Staiger and Stock (1997) that the F-statistic should be at least 10 for weak identification not to be considered a problem". The K-P statistics in Table 6 are much greater than this threshold, and the coefficient on the instrument is highly significant in the first stage regressions (not reported here), which suggests that the estimates are unlikely to suffer from the weak instrument problem.

Table 6

Exposure to Comedy Movies and Stock Returns - IV Estimation

This table displays a subset of the coefficients resulting from estimating model [1] by 2SLS using an instrument for COM. Columns (1) and (2) show the estimates obtained using the entire sample, whereas sub-sample estimates are reported in columns (3) through (6). HAC robust standard errors are shown in parenthesis below the corresponding coefficients. One, two, and three asterisks denote statistical significance at the ten, five, and one percent level, respectively. Returns are measured in percentage points.

\begin{tabular}{|c|c|c|c|c|c|c|}
\hline Dep. Var.: & $\begin{array}{c}\text { Equal- } \\
\text { Weighted } \\
\text { Returns }\end{array}$ & $\begin{array}{c}\text { Value- } \\
\text { Weighted } \\
\text { Returns }\end{array}$ & $\begin{array}{c}\text { Equal- } \\
\text { Weighted } \\
\text { Returns }\end{array}$ & $\begin{array}{c}\text { Value- } \\
\text { Weighted } \\
\text { Returns }\end{array}$ & $\begin{array}{c}\text { Equal- } \\
\text { Weighted } \\
\text { Returns }\end{array}$ & $\begin{array}{c}\text { Value- } \\
\text { Weighted } \\
\text { Returns }\end{array}$ \\
\hline & \multicolumn{2}{|c|}{ Full sample } & \multicolumn{2}{|c|}{$12 / 1 / 1994-6 / 20 / 2002$} & \multicolumn{2}{|c|}{$6 / 21 / 2002-12 / 31 / 2009$} \\
\hline & (1) & (2) & (3) & (4) & (5) & (6) \\
\hline$\alpha$ & $\begin{array}{c}0.165^{* * * *} \\
(0.001)\end{array}$ & $\begin{array}{c}0.128 * * * \\
(0.002)\end{array}$ & $\begin{array}{c}0.188^{* * *} \\
(0.001)\end{array}$ & $\begin{array}{c}0.157 * * * \\
(0.005)\end{array}$ & $\begin{array}{c}0.147 * * \\
(0.026)\end{array}$ & $\begin{array}{c}0.089 \\
(0.168)\end{array}$ \\
\hline$\beta_{\mathrm{COM}}$ & $\begin{array}{c}-0.2189 * * \\
(0.1005)\end{array}$ & $\begin{array}{c}-0.2382 * * \\
(0.1099)\end{array}$ & $\begin{array}{r}-0.0649 \\
(0.496)\end{array}$ & $\begin{array}{c}-0.0912 \\
(0.451)\end{array}$ & $\begin{array}{c}-0.3349 * * \\
(0.019)\end{array}$ & $\begin{array}{c}-0.3272 * * \\
(0.027)\end{array}$ \\
\hline$\beta_{\text {SPECT }}$ & $\begin{array}{c}0.092 \\
(0.155)\end{array}$ & $\begin{array}{c}0.019 \\
(0.192)\end{array}$ & $\begin{array}{l}0.008 \\
(0.962)\end{array}$ & $\begin{array}{c}-0.042 \\
(0.861)\end{array}$ & $\begin{array}{c}0.109 \\
(0.679)\end{array}$ & $\begin{array}{c}0.059 \\
(0.844)\end{array}$ \\
\hline$\gamma_{M}$ & $\begin{array}{l}1.586 \\
(2.490)\end{array}$ & $\begin{array}{c}3.231 \\
(3.005)\end{array}$ & $\begin{array}{c}0.598 \\
(0.826)\end{array}$ & $\begin{array}{c}2.042 \\
(0.569)\end{array}$ & $\begin{array}{l}3.108 \\
(0.496)\end{array}$ & $\begin{array}{c}3.902 \\
(0.452)\end{array}$ \\
\hline$\gamma_{\mathrm{TAX}}$ & $\begin{array}{c}0.229 \\
(0.161)\end{array}$ & $\begin{array}{c}0.105 \\
(0.182)\end{array}$ & $\begin{array}{l}0.157^{*} \\
(0.086)\end{array}$ & $\begin{array}{l}-0.047 \\
(0.795)\end{array}$ & $\begin{array}{c}0.256 \\
(0.462)\end{array}$ & $\begin{array}{c}0.304 \\
(0.354)\end{array}$ \\
\hline $\begin{array}{l}\text { Instrumenting } \\
\text { for } C O M\end{array}$ & $\mathrm{X}$ & $\mathrm{X}$ & $\mathrm{X}$ & $\mathrm{X}$ & $\mathrm{X}$ & $\mathrm{X}$ \\
\hline Observations & 3794 & 3794 & 1897 & 1897 & 1897 & 1897 \\
\hline F statistic & 6.04 & 1.29 & 12.25 & 2.10 & 2.02 & 1.69 \\
\hline $\begin{array}{l}\text { Endogeneity test } \\
\text { (C-statistic) }\end{array}$ & $2.61 *$ & $3.09 *$ & $5.23 * *$ & $6.86 * * *$ & 0.98 & 0.67 \\
\hline $\begin{array}{l}\text { Kleibergen-Paap } \\
\text { Wald rk F statistic }\end{array}$ & 251.9 & 252.1 & 162.6 & 162.6 & 129.8 & 129.8 \\
\hline
\end{tabular}


According to the IV regression, other things equal, a one-standard-deviation increase in comedy film admissions on a given weekend is estimated to be followed by roughly a $0.11 \%$ fall in U.S. stock returns on the following Monday (see the formula in footnote 10 ). ${ }^{15}$ This marginal effect is statistically significant at the $5 \%$ level, and it also appears to be economically relevant: its magnitude is nearly three times the size of the value-weighted unconditional daily mean return $(0.04 \%)$, and some profitable trading strategies could be built upon it. ${ }^{16}$ Conversely, the coefficient on SPECT is not statistically distinguishable from zero. ${ }^{17}$ These numbers confirm that, holding constant the total number of people that go to the movies on a given weekend, an increase in the number of individuals who are exposed to comedies is followed by a decrease in equity returns. Put another way, the estimates are consistent with the view that, while moviegoing per se has no impact on the demand for risky assets (relative to the foregone activity), exposure to happy movies seems to have a negative impact on such a demand. ${ }^{18}$

\subsection{Sub-sample Analysis}

The sample period under scrutiny covers an era that saw profound changes alter the structure of the U.S. stock market. Following the advent of the Internet, the phenomenal growth of

\footnotetext{
${ }^{15}$ It is worth noticing that the Monday dummy appears both alone and interacted with COM and SPECT in model [1], so the "Monday effect" in this context depends on the values of the latter two variables. For example, in the case of the equal-weighted (value-weighted) returns, evaluating the marginal effect of $M$ at the mean values of $\ln (C O M)$ and $\ln ($ SPECT $)$, one finds that stock returns are estimated to fall by around $0.18 \%(0.06 \%)$ on the "average" Monday.

${ }^{16}$ Though it is beyond the scope of this paper to closely examine this issue, assuming transaction costs of one basis point per transaction (see Hirshleifer and Shumway, 2003), when equal-weighted (value-weighted) returns are considered, a strategy that is short the market index on the Mondays following a "high-comedy" weekend and long the market index otherwise outperforms a buy-and-hold strategy by about 3.34\% (2.81\%) per year over the sample period.

${ }^{17}$ In unreported analyses, I included a supplementary instrument meant to capture the average "quality" of the comedy movies playing on a given weekend. To measure the quality of a comedy movie I collected the average rating assigned to said movie by U.S. users of the Internet Movie Database (IMDB), a popular website that collects information about movies, TV shows, actors, and the like. Adding this instrument left the results qualitatively unchanged.

${ }^{18}$ In unreported analyses, I also controlled for the number of spectators watching violent movies and thrillers, as previous research has shown that exposure to violent media can elicit transient aggressive behaviors in the viewer (e.g. Anderson, 1997; Huesmann and Taylor, 2006), and the latter have been found to be positively related to risk-taking propensity (e.g. Caspi et al., 1997; Krcmar and Greene, 2000). The results were qualitatively identical to the ones reported in Table 6 .
} 
online trading between the end of the 1990s and the beginning of the next decade revolutionized how stock trading is conducted by individual investors. Up to 1994, electronic brokerage was practically nonexistent, but over the next decade the number of U.S. e-brokerages grew exponentially (Konana et al., 2000), and the number of online trading accounts rose from 1.5 million in 1997 to 50 million in 2004 (Baumol and Blinder, 2011). Since there is evidence that said revolution has increased the portion of naïve investors in the market (Ahmed et al., 2003; Barber and Odean, 2001), and unsophisticated investors are believed to be more sensitive to sentiment than institutional investors (Lee et al., 1991; Kumar and Lee, 2006), according to the analysis presented in the previous sections one would expect to observe a stronger impact of comedy-induced mood on stock prices in the more recent period. To explore this issue, I therefore divide the original sample into two equal-size sub-samples and run the IV regression separately for each of them. The results, reported in columns (3) through (6) of Table 6, reveal that the sign of the coefficient on COM is stable across time, but its magnitude is noticeably larger in the second sub-period, consistently with the view that the effect of investor mood on the pricing of stocks is stronger when there is a greater number of inexperienced investors in the market. The coefficient on $C O M$ is statistically different from zero in the second sub-period, but not in the first one, whereas the hypothesis that the coefficient on SPECT is equal to zero cannot be rejected in both sub-samples. The remaining variables show similar patterns across time.

\subsection{Robustness Tests}

In principle, liquidity effects and other market frictions may be responsible for the effect documented in the previous sections. For instance, going out on the weekend to watch a comedy movie may imply that investors will have less time to catch up with the economic news, assess their portfolios, and evaluate potential trading decisions. As a result, if they feel uninformed and unready 
to trade, they may decide to simply stay away from the market on the following Monday, thus causing a reduced order flow. A fall in liquidity may then persuade sellers to accept a lower price, hence depressing stock returns. Following Tetlock (2007), here I control for this type of liquidity effects and other possible market frictions using trading volume and lagged return volatility. More specifically, I employ a time series of daily trading volume on the NYSE, which I detrend after a logarithmic transformation of the data. ${ }^{19}$ I also use the detrended squared residuals of the CRSP returns as a proxy for past volatility. ${ }^{20}$ I then re-estimate model [1] adding up to five lags of these two controls and instrumenting for COM as described in the previous section. The results for the equal-weighted returns and value-weighted returns are shown in column (1) and (2) of Table 7 , respectively. The coefficient on $C O M$ is once again estimated to be negative and statistically significant, and its magnitude is virtually unaffected by the inclusion of these two covariates, which suggests that the mood effect documented here is not driven by a drop in market liquidity (at least when liquidity is proxied by trading volume) or by other market frictions (as measured here).

One may also worry that the seasonal controls included in model [1] do not completely remove the seasonal patterns that may affect both comedy movie attendance and stock returns. For instance, holidays typically increase movie attendance (Einav, 2007), and there is also evidence of abnormal stock market behaviors around their occurrence (e.g. Ariel, 1990; Kim and Park, 2009). In principle, holidays might have a distinctive effect on $C O M$ that is not already captured by the dynamics of SPECT or by the monthly dummies. I therefore add to model [1] separate dummy indicators that take value 1 on the Mondays following the major U.S. holidays (and 0 otherwise): New Year's Day, Independence Day, Veteran's day, Thanksgiving Day, Christmas Day, and Easter

\footnotetext{
${ }^{19}$ Trading volume data are taken from Datastream (code: TVNYORK(VO)). As in Campbell, Grossman and Wang (1993) and Tetlock (2007), I detrend the data by subtracting the 60-day moving average of log daily volumes from the current log volume. All the results reported in the paper stay virtually unchanged when using the 30-day or 90-day moving average.

${ }^{20}$ As in Tetlock (2007), first I demean the stock returns series to obtain a residual, then I square this residual and I subtract the 60-day moving average of past squared residuals. The results reported below are robust to the use of a $30-$ day or 90-day moving average.
} 
Day. The results for the equal-weighted returns and value-weighted returns are displayed in column

(3) and (4) of Table 7, respectively. What emerges is that adding all these covariates does not alter

the signs, magnitudes, and statistical significance of the coefficients on COM and SPECT. ${ }^{21}$

Table 7

Exposure to Comedy Movies and Stock Returns - Robustness Checks

This table displays a subset of the coefficients resulting from estimating model [1] by 2SLS, instrumenting for COM, and including some additional controls (marked by an X). The coefficients on the five lagged returns and monthly dummies are not reported due to space limitations. HAC robust standard errors are shown in parenthesis below the corresponding coefficients. One, two, and three asterisks denote statistical significance at the ten, five, and one percent level, respectively. Returns are measured in percentage points.

\begin{tabular}{lcccc}
\hline \multirow{2}{*}{ Dep. Var.: } & $\begin{array}{c}\text { Equal-Weighted } \\
\text { Returns }\end{array}$ & $\begin{array}{c}\text { Value-Weighted } \\
\text { Returns }\end{array}$ & $\begin{array}{c}\text { Equal-Weighted } \\
\text { Returns }\end{array}$ & $\begin{array}{c}\text { Value-Weighted } \\
\text { Returns }\end{array}$ \\
\cline { 2 - 5 }$\alpha$ & $(1)$ & $(2)$ & $(3)$ & $(4)$ \\
\cline { 2 - 5 }$\beta_{\text {COM }}$ & $0.179^{* * *}$ & $0.149^{* * *}$ & $0.183^{* * *}$ & $0.148^{* * *}$ \\
& $(0.001)$ & $(0.002)$ & $(0.001)$ & $(0.003)$ \\
$\beta_{\text {SPECT }}$ & $-0.2168^{* *}$ & $-0.2535^{* *}$ & $-0.2146^{* *}$ & $-0.2519^{* *}$ \\
& $(0.0982)$ & $(0.1084)$ & $(0.1002)$ & $(0.1112)$ \\
$\gamma_{\mathrm{M}}$ & 0.180 & 0.075 & 0.2058 & 0.107 \\
$\gamma_{\text {TAX }}$ & $(0.162)$ & $(0.198)$ & $(0.171)$ & $(0.206)$ \\
Instrumenting for Comedy & 0.069 & 2.521 & -0.382 & 1.984 \\
Liquidity and Market Frictions & $(2.295)$ & $(3.035)$ & $(2.543)$ & $(3.228)$ \\
Controls & 0.095 & 0.049 & 0.036 & 0.014 \\
Holiday Controls & $(0.154)$ & $(0.173)$ & $(0.154)$ & $(0.180)$ \\
Observations & $\mathrm{X}$ & $\mathrm{X}$ & $\mathrm{X}$ & $\mathrm{X}$ \\
F statistic & & & & $\mathrm{X}$ \\
Kleibergen-Paap Wald rk F & & $\mathrm{X}$ & $\mathrm{X}$ & $\mathrm{X}$ \\
statistic & & & $\mathrm{X}$ & 3752 \\
\hline
\end{tabular}

\footnotetext{
${ }^{21}$ In unreported analyses, I have also added to model [1] a set of financial controls: the one-day lagged junk bond premium, the one-day lagged yield curve spread, the one-day lagged VIX index (e.g. Hatemi-J and Irandoust, 2011), and the aggregate performance of the stock market over the previous month (or week, or three months). The last variable can be considered as a proxy for medium-term investor sentiment. Including said variables does not alter the results presented in the table. I thank an anonymous reviewer for suggesting this robustness check.
} 
In my analysis so far I have defined a movie as a comedy if it has been classified in the "comedy" genre by www.the-numbers.com. It is natural to wonder whether the findings are sensitive to alternative movie categorizations. In order to explore this issue I construct some alternative definitions of a comedy movie. First, I consider a movie as a comedy if it has been labelled by $w w w . t h e-n u m b e r s . c o m$ as either a "comedy" or a "romantic comedy". In a second exercise, I consider a movie as a comedy if it has been classified either as a "comedy" or a "black comedy". ${ }^{22}$ In a third exercise, I combine "comedies", "romantic comedies", and "black comedies" into a single group. I then re-estimate model [1] instrumenting for COM and tweaking the instrument based on the three new definitions of a comedy movie. The results, not reported here due to space limitations, suggest that, under all these three alternative definitions, the coefficient on $C O M$ is estimated to be negative and statistically significant at the 5\% level. Furthermore, using anyone of these three alternative definitions slightly increases the magnitude (in absolute value) of the marginal effect of $C O M$, which suggests that the original definition may be considered as a conservative one. More specifically, when employing the most general definition of a comedy movie that embraces all three genre labels ("comedy", "romantic comedy", and "black comedy"), I estimate than a one-standard-deviation increase in comedy movie attendance on a given weekend lowers U.S. stock returns by $0.14 \%$ on the following Monday.

In order to verify whether the findings are sensitive to outliers, I also re-estimate model [1] (using the benchmark instrument) including a dummy indicator for the $1 \%$ of observations with the largest comedy movie attendance. I repeat the same exercise using a $2 \%$ and $3 \%$ cut-off rule, respectively, and also including a dummy indicator for the $1 \%(2 \%, 3 \%)$ of observations with the

\footnotetext{
${ }^{22}$ The average audience size for movies belonging to the "romantic comedy" or "black comedy" genres is much smaller than for movies falling into the "comedy" genre. On a typical weekend, "comedies" are watched by 4.67 million people, whereas "romantic comedies" and "black comedies" are watched by 1.16 million and 85 thousand people, respectively (see Table 1).
} 
smallest number of comedy admissions. The sign, size, and statistical significance of the estimated coefficient on $C O M$ turn out to be qualitatively unaffected by these additions.

Last, to test whether the results are robust to alternative measures of aggregate equity returns, I employ the returns on some broad indices of the U.S. stock market in place of the CRSP returns, which extends the sample period up to May 31, 2010. More in detail, I compute equity returns using the S\&P500, the Dow Jones Industrial, the NYSE Composite, and the Nasdaq Composite index, respectively. I then re-estimate model [1] using the benchmark instrument for COM and what emerges from the estimates (not reported here) is that, independently of the market index adopted, the marginal effect of $C O M$ is estimated to be negative and statistically significant at conventional levels. The largest point estimate (in absolute value) is found when analyzing the Nasdaq index, in which case I find that a one-standard-deviation rise in comedy admissions reduces Monday returns by $0.18 \%$. The smallest effect pertains to the Dow index, in which case Monday returns are estimated to fall by approximately $0.08 \%$. This pattern is indeed consistent with the mood-effect story presented here: since large-cap stocks feature a higher institutional ownership than small cap-stocks (e.g. Lee et al., 1991) and institutional investors are believed to be less sensitive to irrational factors (e.g. sentiment) than retail investors (e.g. Kumar and Lee, 2006), one would precisely expect to observe a stronger mood effect when analyzing the Nasdaq index than the Dow.

\subsection{Examining the Cross-Section of Stock Returns}

The last portion of my analysis is devoted to shedding more light on the link of causality by examining the cross section of stock returns. Investor sentiment is believed to exert a larger influence on the pricing of stocks whose intrinsic values are highly subjective and that are more difficult to arbitrage. Baker and Wurgler (2006) find evidence that behavioral biases are stronger for 
(among others) high-volatility stocks. I therefore re-estimate model [1] using as a dependent variable the CRSP returns calculated on standard deviation-based deciles and instrumenting for $C O M$ as described in section 5.3.2. The results, depicted in Figure 3 (panel a), reveal a nearly monotonic volatility effect. The first decile (highest standard deviations) exhibits the largest marginal effect of COM (significant at the 1\% level) and the magnitude of this effect progressively decreases (in absolute value) with the volatility deciles. Considering the first decile, a one-standarddeviation increase in comedy film admissions is estimated to be followed by a $0.16 \%$ decrease in Monday returns. In the case of the lowest volatility decile, though the size of the coefficient is still negative, the effect is no longer statistically significant at conventional levels.

Kumar (2009) documents that investor sentiment has a stronger impact on stocks featuring high cash flow volatility and earnings volatility, the rationale being that these two factors increase valuation uncertainty. Here I employ a classification of firms by industry, as firms belonging to less stable industries (e.g. high-tech) tend to experience higher cash flow and earnings volatility than firms belonging to stable ones (e.g. utilities) (Kim et al., 2008; Dichev and Tang, 2009). I therefore re-estimate model [1] using as a dependent variable the returns on the ten Fama and French (1992) value-weighted portfolios constructed by industry. The results, displayed in Figure 3 (panel b) reveal that the most volatile industries (HiTech, Other, Durbl, and Telcm) tend to cluster on one side of the industry spectrum (featuring the strongest mood effects), while the most stable ones (Nodur, Utils) tend to cluster on the opposite side. ${ }^{23}$ Furthermore, the coefficient on COM is statistically significant at conventional levels only when the most volatile industries are considered.

\footnotetext{
${ }^{23}$ The Other portfolio contains firms from the following industries: building materials, business services, construction, entertainment, finance, hotels, mines, and transportation.
} 
Intended for color reproduction on the

Web, black-and-white in print.

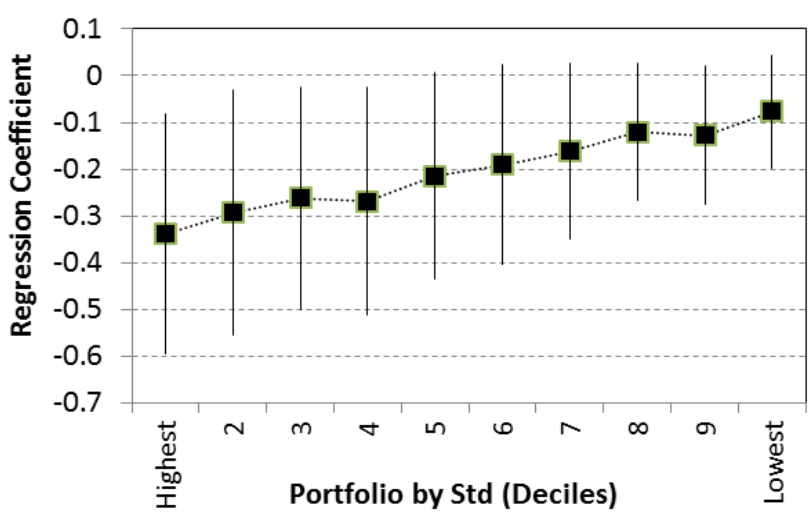

(a)

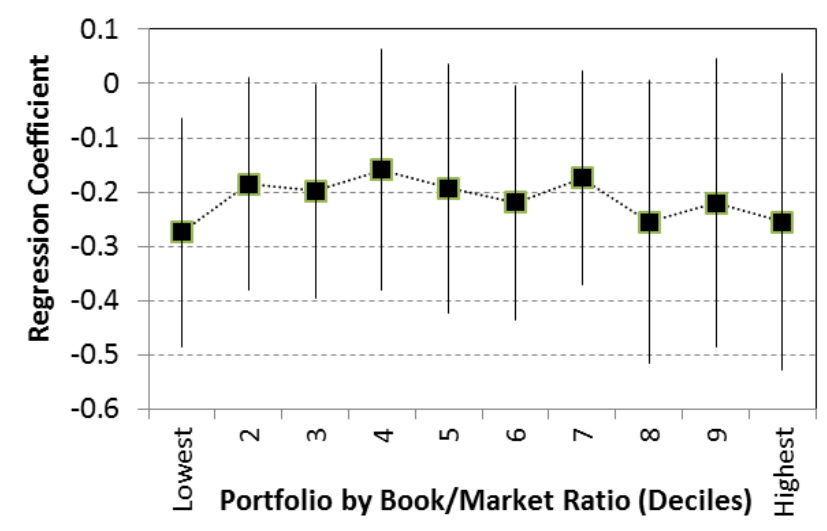

(c)

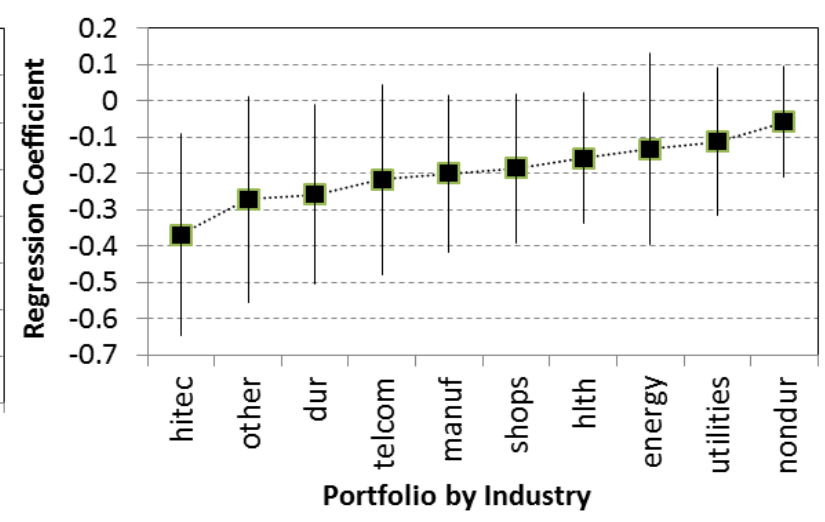

(b)

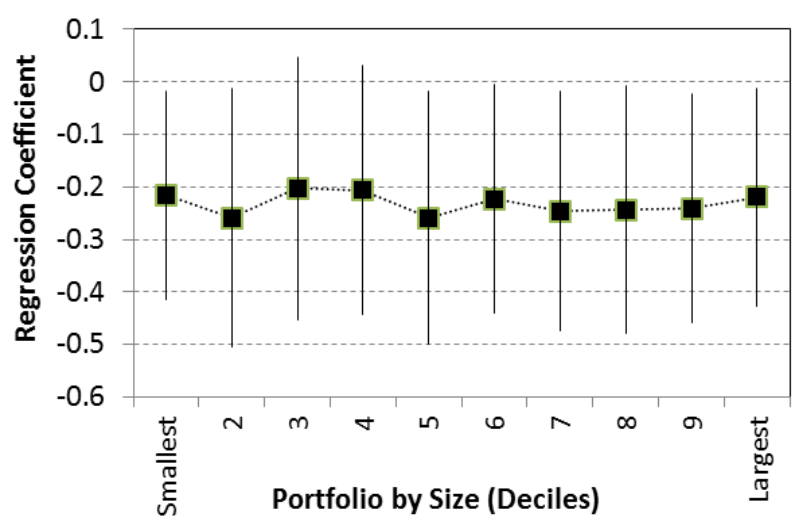

(d)

Figure 3. Movie-induced positive mood effect and firm characteristics. The figure depicts the point estimates and $95 \%$ confidence intervals of the mood effect (i.e. the coefficient on COM) for ten CRSP portfolios constructed by standard deviation (panel a) and ten Fama and French (1992) portfolios constructed by industry (panel b), book-to-market ratio (panel c), and size (panel d).

Baker and Wurgler (2006) also find support for the view that smaller stocks, extremegrowth stocks, and distressed stocks are more likely to be subject to behavioral biases. Based on this insight, here I examine the behavior of the returns on the ten Fama and French (1992) portfolios sorted by book-to-market ratio and size. Baker and Wurgler (2006) suggest that exceedingly high book-to-market ratios may signal distressed stocks, whereas exceedingly low book-to-market ratios 
may signal extreme-growth stocks. Based on this interpretation, the mood effect analyzed here should be expected to follow an inverted U-shape pattern, with the strongest impact at the two ends of the book-to-market range. Such a pattern is indeed noticeable in Figure 3 (panel c), which provides some additional favorable evidence. However, the difference between the middle and the top (or bottom) deciles is relatively small and statistically insignificant. Lastly, when the portfolios sorted by size are analyzed, no clear pattern emerges (see Figure 3 (panel d)), but the coefficient on COM is always estimated to be negative, and in most instances it is statistically significant at least at the $5 \%$ level.

\section{Concluding remarks}

In this study, by exploiting the natural experiment provided by the time-series variation in the theatrical release of comedy movies, I find that a rise in the number of people exposed to a comedy movie on a given weekend is followed by a fall in stock returns on the subsequent Monday. The theoretical foundation underpinning this result can be found in the experimental psychology literature. According to the MMH, exposure to happy movie clips, by triggering positive mood, induces people to behave more cautiously and avoid risk, especially when the stakes are high and large losses are possible, in order to preserve their good emotional states. The empirical findings are consistent with the interpretation that the wave of positive mood stemming from a wider population exposure to comedy movies causes a decrease in risk-taking propensity across investors and a shortterm drop in the demand for risky assets, thus adversely affecting equilibrium prices in the stock market. The fact that the pricing of sentiment-sensitive stocks tends to be affected by this phenomenon to a greater extent suggests that these empirical patterns are unlikely to be due to unobserved economic factors. 
Compared to the existing observational studies on the relationship between mood and investment in risky assets, this investigation is more deeply rooted into the available experimental evidence, as it focuses directly on a mood-shifting mechanism (i.e. exposure to happy clips) that is widely employed in the laboratory, thus allowing a more direct comparison of the results. It should be highlighted that the evidence that I present is in contrast to the findings of e.g. Hirshleifer and Shumway (2003). These authors argue that positive investor mood (supposedly triggered by sunshine) has a positive impact on stock returns. The data that I analyze seem to tell the opposite story and are consistent with the field evidence presented by Guven (2009) and the lab evidence that supports the MMH. It might be the case that not all happy moods are alike, and the source of a mood state plays a relevant role that should be taken into account. Future research should investigate this issue and also ensure that the approaches employed in the field are replicated in the lab (and vice versa). With regard to the specific findings of this study, it would be interesting to expand the analysis to other countries where moviegoing is a prevalent leisure activity. 


\section{Appendix}

The environmental controls are constructed using data from several sources. From the behavioral finance literature I identify a set of factors that are believed to affect people's moods and, in turn, have an impact on stock returns. Following Kamstra et al. (2003), to capture the Seasonal Affective Disorder (SAD) effect I construct a Fall dummy and a $S A D$ variable that measures the standardized daily hours of night in New York City. In the spirit of Yuan et al. (2006), to control for the influence of the lunar cycle, I construct a full-moon dummy that takes value 1 up to three days before and after each full moon date and 0 otherwise, and a new-moon dummy that takes value 1 up to three days before and after each new moon date. In the spirit of Krivelyova and Robotti (2003), using the c9 geomagnetic index provided by the National Geophysical Data Center in Boulder (CO), I construct a dummy variable that takes value 1 on the three days that follow a sizable disturbance in the Earth's magnetosphere (c9 index $\geq 7$ ) and 0 otherwise. Following Cao and Wei (2005), Hirshleifer and Shumway (2003), and Keef and Roush (2002), I create a time series of daily average temperature $\left(\mathrm{F}^{\circ}\right)$, rainfall (a dummy taking value 1 if a positive amount of rain falls on day $t$ and 0 otherwise), and wind speed (knots) in New York City using data from the National Climatic Data Center in Asheville (NC).

Finally, to control for broad weather patterns within the U.S. that may influence the mood of a large fraction of the population (and, as a result, its investment decisions, leisure choices, and movie selections), I follow Dahl and DellaVigna (2009)'s approach and I construct a set of environmental controls that capture widespread hot and cold temperatures, as well as other weather features. More specifically, for the capital of each U.S. state I collect information about the maximum daily temperature $\left(\mathrm{F}^{\circ}\right)$, minimum daily temperature, and maximum wind speed (knots), and I construct six dummy variables for the daily occurrence of rain, snow, fog, hail, thunderstorms, 
and tornados. ${ }^{24}$ All data are obtained from the National Climatic Data Center in Asheville (NC). I then convert the state-level temperature and wind speed variables into dummy variables as follows: three dummies are constructed for the maximum daily temperature falling in one of three classes $\left(80<\mathrm{F}^{\circ} \leq 90 ; 90<\mathrm{F}^{\circ} \leq 100 ; \mathrm{F}^{\circ}>100\right)$, three dummies are constructed for the minimum daily temperature falling in one of three classes $\left(\mathrm{F}^{\circ} \leq 10 ; 10<\mathrm{F}^{\circ} \leq 20 ; 20<\mathrm{F}^{\circ} \leq 32\right)$, and two dummies for the maximum wind speed falling in one of two classes $(17<$ knots $\leq 21$; knots $>21)$. For each of the resulting 14 state-level weather dummy variables I then construct a daily national weighted average using as weights the relevant state populations. ${ }^{25}$ The resulting 14 national weather times series have an intuitive interpretation: each of them proxies for the percentage of the U.S. population that on day $t$ is exposed to a specific weather phenomenon (e.g. rain, snow, high temperatures, etc).

\footnotetext{
${ }^{24}$ There are three exceptions. In the case of Kentucky, Maryland, and Nevada I employ weather data for Lexington, Baltimore, and Reno, respectively. This choice is guided by the availability of data.

${ }^{25}$ Population figures by state are taken from the U.S. Census Bureau. I assign a missing value to the daily national weighted average of a given weather variable when the missing state-level data account for more than $10 \%$ of the U.S. population. When the missing state-level weather data account for less than $10 \%$ of the U.S. population, I use only the available state-level data to compute the daily national weighted average.
} 


\section{References}

Abraham A. and D. L. Ikenberry (1994). The Individual Investor and the Weekend Effect, Journal of Financial and Quantitative Analysis, 29, pp. 263-277.

Ahmed A., R. Schneible Jr., and D. Stevens, D. (2003). An empirical analysis of the effects of online trading on stock price and trading volume reactions to earnings announcements, Contemporary Accounting Research, 20(3), pp. 413-39.

Al-Hajieh H., K. Redhead, and T. Rodgers (2011). Investor sentiment and calendar anomaly effects: A case study of the impact of Ramadan on Islamic Middle Eastern markets, Research in International Business and Finance, 25(3), pp. 345-356.

Anderson C. A. (1997). Effects of violent movies and trait hostility on hostile feelings and aggressive thoughts, Aggressive Behavior, 23, pp. 161-178.

Andrade E. and D. Ariely (2009). The enduring impact of transient emotions on decision making, Organizational Behavior and Human Decision Processes, 109, pp. 1-8.

Andrade E. and J. B. Cohen (2007). Affect-Based Evaluation and Regulation as Mediators of Behavior: The Role of Affect in Risk Taking, Helping and Eating Patterns. To appear in: Vohs, K.D., Baumeister, R.F, and Loewenstein, G. (2007). Do emotions help or hurt decision making? Perspectives from psychology and economics. New York: Russell Sage.

Arbitron (2003). The Arbitron Cinema Advertising Study: Appointment Viewing by Young, Affluent, Captive Audiences, http://www.arbitron.com/study/cinema_study.asp.

Ariel R. A. (1990). High stock returns before holidays: existence and evidence on possible causes, Journal of Finance, 45 (5), pp. 1611-1626.

Arkes H. R., L. T. Herren and A. M. Isen (1988). The role of potential loss in the influence of affect on risk-taking behavior. Organizational Behavior and Human Decision Processes, 42, 181-193.

Au K., F. Chan, D. Wang and I. Vertinsky (2003). Mood in foreign exchange trading: Cognitive processes and performance, Organizational Behavior and Human Decision Processes, 91, pp. 322-338.

Baker M. and J. Wurgler (2006). Investor sentiment and the cross-section of stock returns, Journal of Finance, 61, pp. 1645-1680.

Barber B. M. And T. Odean (2001). The Internet and the investor, Journal of Economic Perspectives, 15(1), pp. 41-54. 
Baum C. F., M. E. Schaffer and S. Stillman (2007). Enhanced routines for instrumental variables/generalized method of moments estimation and testing, Stata Journal, 7 (4), pp. 465-506.

Baum C. F., M. E. Schaffer and S. Stillman (2010), IVREG2: Stata module for extended instrumental variables/2SLS and GMM estimation, Statistical Software Components, Boston College Department of Economics.

Baumol W. and A. Blinder (2011). Microeconomics: principles and policy, Twelfth edition. SouthWestern, Cengage Learning.

Baur D. G. (2013). The autumn effect of gold, Research in International Business and Finance, 27(1), pp. 1-11.

Bertaut C. (1998). Stockholding Behavior of U.S. Households: Evidence from the 1983-1989 Survey of Consumer Finances, Review of Economics and Statistics, 80(2), pp. 263-75.

Bogan V. (2008). Stock Market Participation and the Internet, Journal of Financial and Quantitative Analysis, 43, pp. 191-211.

Bower G. H. (1981). Mood and memory, American psychologist, 36(2), pp. 129-148.

Campbell J., Y., S. J. Grossman and J. Wang (1993). Trading volume and serial correlationin stock returns, Quarterly Journal of Economics, 108, pp. 905-939.

Cao M., and J. Wei (2005). Stock market returns: a note on temperature anomaly, Journal of Banking and Finance, 29, pp. 1559-1573.

Caspi A., D. Begg, N. Dickson, H. L. Harrington, J. Langley, T. E. Moffitt and P. A. Silva (1997). Personality differences predict health-risk behaviors in young adulthood: Evidence from a longitudinal study, Journal of Personality and Social Psychology, 73, pp. 1052-1063.

Chan S. H., W. K. Leung, and K. Wang (2004). The Impact of Institutional Investors on the Monday Seasonal, Journal of Business, 77(4), pp. 967-988.

Chou K., Lee T. M. C., And A. H. Y. Ho (2007). Does Mood State Change Risk Taking Tendency In Older Adults?, Psychology And Aging, 22(2), pp. 310-317.

Dahl G. and S. DellaVigna (2009). Does Movie Violence Increase Violent Crime?, Quarterly Journal of Economics, 124, pp. 677-734.

Dichev I. D., and V. W. Tang (2009). Earnings volatility and earnings predictability, Journal of Accounting and Economics, 47, pp. 160-181.

Dyl, E.A. and Maberly, E.D. (1992). Odd-lot transactions around the turn of the year and the January effect. Journal of Financial and Quantitative Analysis, 27, pp. 591-604. 
Edmans A., D Garcia and Ø. Norli (2007). Sports sentiment and stock returns, The Journal of Finance, 62(4), pp. 1967-1998.

Einav L. (2007). Seasonality in the U.S. Motion picture industry. Rand Journal of Economics, 38(1), pp. 127-145.

Fama E. and French K. (1992). The cross-section of expected stock returns. Journal of Finance, 47, pp. 427-467.

Forgas J. P. (1995). Mood and judgment: The affect infusion model (AIM). Psychological Bulletin, 117, 39-66.

Forgas, J. P. (1998). Happy and mistaken? Mood effects on the fundamental attribution error. Journal of Personality and Social Psychology, 75, 318-331.

Forgas J. P. and G. H. Bower (1987). Mood effects on person-perception judgments, Journal of personality and social psychology, 53(1), pp. 53-60.

Forgas J. P. And S. Moylan (1988). After the movies: transient mood and social judgments, Personality and Social Psychology Bulletin, 13(4), pp. 467-477.

Gibbons M. R. and P. Hess (1981). Day of the Week Effects and Asset Returns, The Journal of Business, 54(4), pp. 579-596.

Grable J. E. and M. J. Roszkowski (2008). The influence of mood on the willingness to take financial risks, Journal of Risk Research, 11(7), pp. 905-923.

Guiso L., M. Haliassos, and T. Jappelli (2003). Stockholding in Europe: where do we stand, and where do we go?, Economic Policy, 36, pp. 123-70.

Guven C. (2009). Weather and Financial Risk-Taking: Is Happiness the Channel?, SOEP paper No. 218. Available at SSRN: http://ssrn.com/abstract=1476884.

Hatemi-J A. and M. Irandoust (2011). The dynamic interaction between volatility and returns in the US stock market using leveraged bootstrap simulations, Research in International Business and Finance, 25(3), pp. 329-334.

Heath D. (2007). Affect and Choice: Induced Emotion Affects Economic Decisions, Working paper, Chicago Graduate School of Business.

Hirshleifer D., and T. Shumway (2003). Good day sunshine: stock returns and the weather, Journal of Finance, 58, pp. 1009-1032.

Hong H., J. D. Kubik, and J. C. Stein (2004). Social interaction and stock market participation, Journal of Finance, 59, pp. 137-63. 
Huesmann L. R. and L. D. Taylor (2006). The Role of media Violence in Violent Behavior, Annual Review of Public Health, 27, pp. 393-415.

Hull R. B. and S. E. Michael (1995). Nature-based recreation, mood change, and stress restoration, Leisure Sciences, 17, pp. 1-14.

Isen A.M. and N. Geva (1987). The influence of positive affect on acceptable level of risk: the person with a large canoe has a large worry, Organizational Behavior and Human Decision Processes, 39, pp. 145-154.

Isen A. M., T. E. Nygren and F. G. Ashby (1988). Influence of Positive Affect on the Subjective Utility of Gains and Losses: It Is Just Not Worth the Risk, Journal of Personality and Social Psychology, 55(5), pp. 710-717.

Isen A. M. and R. Patrick (1983). The Effect of Positive Feelings on Risk Taking: When the Chips Are Down. Organizational and Human Behavior, 31, pp. 194-202.

Isen A. M., T. E. Shalker, M. Clark and L. Karp (1978). Affect, accessibility of material in memory, and behavior: A cognitive loop?, Journal of Personality and Social Psychology, 36(1), pp.1-12.

Johnson, E. J. and Tversky, A. (1983). Affect, generalization and the perception of risk, Journal of personality and social psychology, 45, pp. 20-31.

Kamstra M. J., L. A. Kramer, and M. D. Levi (2003). Winter blues: a SAD stock market cycle, American Economic Review, 93, pp. 324-341.

Keef S. P. and M. Roush (2002). Influence of Weather on New Zealand Financial Securities, Accounting and Finance, 45(3), pp. 415-437.

Keim D.B. (1983). Size-related anomalies and stock return seasonality: Further empirical evidence. Journal of Financial Economics, 12, pp. 13-32.

Kim C. W. and J. Park (2009). Holiday effects and stock returns: Further evidence, Journal of Financial and Quantitative Analysis, 29, pp. 145-157.

Kim J., K. Pukthuanthong-Le, T. Walker (2008). Leverage and IPO under-pricing: high-tech versus low-tech IPOs, Management Decision, 46(1), pp.106-130.

Kleibergen, F., and R. Paap (2006). Generalized reduced rank tests using the singular value decomposition, Journal of Econometrics, 127(1), pp. 97-126.

Konana P., N. M. Menon, and S. Balasubramanian (2000). The implications of online investing, Communications of the ACM, 43(1), pp. 35-41. 
Krcmar M. and K. Greene (2000). Connections Between Violent Television Exposure and Adolescent Risk Taking, Mediapsychology, 2, pp. 195-217.

Ko W., L. Yuming, and J. Erickson (1997). A New Look at the Monday Effect, The Journal of Finance, 52(5), pp. 2171-2186.

Krivelyova A. and C. Robotti (2003). Playing the field: geomagnetic storms and the stock market, Working paper No. 2003-5b, Federal reserve bank of Atlanta.

Kumar A. (2009). Hard-to-Value Stocks, Behavioral Biases, and Informed Trading, Journal of Financial and Quantitative Analysis, 44(6), pp. 1375-1401.

Kumar, A. and Lee, C. M. C. (2006), Retail Investor Sentiment and Return Comovements. The Journal of Finance, 61, pp. 2451-2486.

Lang A. (1990). Involuntary attention and physiological arousal evoked by structural features and mild emotion in TV commercials, Communication Research, 17, pp. 275-299.

Lee, C., Shleifer, A., Thaler, T. (1991). Investor sentiment and the closed-end fund puzzle. Journal of Finance, 46, pp. 75-109.

Levi M. (1997). Are Capital Markets Internationally Integrated?, in Thomas J. Courchene and Edwin H. Neave, Reforming the Canadian financial sector. Kingston, Ontario: Queens University Press, pp. 63-84.

Lewis K. K. (1999). Trying to Explain Home Bias in Equities and Consumption, Journal of Economic Literature, 37(2), pp. 571-608.

Lin C., Yen H. R. and S. Chuang (2006). The effects of emotion and need for cognition on consumer choice involving risk, Marketing Letters, 17, pp. 47-60.

Mackie D. M. and L. T. Worth (1991). Feeling good, but not thinking straight: the impact of positive mood on persuasion. In J. Forgas (Ed.), Emotion and social judgment (pp. 201219). Oxford: Pergamon Press.

Mano H. (1994). Risk-taking, framing effects, and affect, Organizational Behavior and Human Decision Processes, 57(1), pp. 38-58.

Moretti E. (2008). Social Learning and Peer Effects in Consumption: Evidence From Movie Sales, NBER Working Paper 13832.

MPAA (2007). Movie attendance study, http://www.immagic.com/eLibrary/ARCHIVES/ GENERAL/ MPAA_US/M080415M.pdf

Newey W. K. and K. D. West (1987). A simple, positive semi-definite, heteroskedasticity and autocorrelation consistent covariance matrix, Econometrica, 55(3), pp. 703-708. 
Newey W. K., and K. D. West (1994). Automatic lag selection in covariance matrix estimation. Review of Economic Studies, 61, pp. 631-653.

Nygren T. E., A. M. Isen, P. J. Taylor and J. Dulin (1996). The Influence of Positive Affect on the Decision Rule in Risk Situations:Focus on Outcome (and Especially Avoidance of Loss) Rather Than Probability, Organizational Behavior and Human Decision Processes, 66(1), pp. 59-72.

Oliver, M. B. (1993). Exploring the paradox of the enjoyment of sad films. Human Communication Research, 19, pp. 315-342.

Oliver, M. B. (2003). Mood management and selective exposure in J. Bryant, D. Roskos-Ewoldsen, \& J. Cantor (Eds.), Communication and Emotion: Essays in Honor of Dolf Zillmann. Mahwah, NJ: Lawrence Erlbaum Associates, Inc.

Reeves B., Thorson E., Rothschild M., McDonald D., Hirsch J. and Goldstein R. (1985). Attention to television: Intrastimulus effects of movement and scene changes on alpha variation over time, International Journal of Neuroscience, 27, pp. 241-255.

Schwarz N. and H. Bless (1991). Happy and mindless, but sad and smart? The impact of affective states on analytic reasoning. In J. P. Forgas (Ed.), Emotion and social judgments (pp. 5571). Oxford, England: Pergamon Press.

Schwarz N. and G. L. Clore (1983). Mood, misattribution, and judgments of well-being: Informative and directive functions of affective states, Journal of personality and social psychology, 45(3), pp. 513-523.

Staiger, D., and J. H. Stock (1997). Instrumental variables regression with weak instruments. Econometrica, 65(3): 557-86.

Tetlock P. (2007). Giving content to investor sentiment: the role of media in the stock market, The Journal of Finance, 62(3), pp. 1139-1168.

van Rooij M., Lusardi A., and R. Alessie (2007). Financial Literacy and Stock Market Participation, University of Michigan Retirement Research Center, WP 2007-162.

Venezia I. and Z. Shapira (2007). On the behavioral differences between professional and amateur investors after the weekend, Journal of Banking \& Finance, 31(5), pp. 1417-1426.

Yuan K., L. Zheng, and Q. Zhu (2006). Are investors moonstruck? Lunar phases and stock returns, Journal of Empirical Finance, 13, pp. 1-23. 
Wegener D. T., Petty R. E. and D. J. Klein (1994). Effects of mood on high elaboration attitude change: the mediating role of likelihood judgments, European journal of social psychology, 24, pp. 25-43.

Westermann R., K. Spies, and G. H. Stahl (1996). Relative effectiveness and validity of mood induction procedures: a meta-analysis, European Journal of Social Psychology, 26, pp. 557-580.

Wright, W.F. and G. H. Bower (1992). Mood effects on subjective probability assessment, Organizational Behavior and Human Decision Processes, 52(2), pp. 276-291.

Zillmann D. (1988). Mood management: Using entertainment media to full advantage. In L. Donohew, H. E. Sypher, \& E. T. Higgins (Eds.), Communication, social cognition and affect (pp. 147-171). Hillsdale, NJ: Lawrence Erlbaum Associates, Inc. 